Open Access

\title{
Design, implementation and evaluation of a training programme for school teachers in the use of malaria rapid diagnostic tests as part of a basic first aid kit in southern Malawi
}

Stefan Witek-McManus ${ }^{1,2^{*}}$, Don P. Mathanga ${ }^{3}$, Allison Verney ${ }^{1}$, Austin Mtali ${ }^{1}$, Doreen Ali ${ }^{4}$, John Sande ${ }^{4}$, Reuben Mwenda ${ }^{5}$, Saidi Ndau ${ }^{6}$, Charles Mazinga ${ }^{7}$, Emmanuel Phondiwa ${ }^{8}$, Tiyese Chimuna ${ }^{1}$, David Melody ${ }^{1}$, Natalie Roschnik ${ }^{9}$, Simon J. Brooker ${ }^{2}$ and Katherine E. Halliday ${ }^{2}$

\begin{abstract}
Background: With increasing levels of enrolment, primary schools present a pragmatic opportunity to improve the access of school children to timely diagnosis and treatment of malaria, increasingly recognised as a major health problem within this age group. The expanded use of malaria rapid diagnostic tests (RDTs) and artemisinin combination therapy (ACT) by community health workers (CHWs) has raised the prospect of whether teachers can provide similar services for school children. We describe and evaluate the training of primary school teachers to use a first aid kit containing malaria RDTs and ACT for the diagnosis and treament of uncomplicated malaria in school children in southern Malawi.
\end{abstract}

Methods: We outline the development of the intervention as: (1) conception and design, (2) pilot training, (3) final training, and (4) 7-month follow up. The training materials were piloted at a four-day workshop in July 2013 following their design at national stakeholders meetings. The evaluation of the pilot training and materials were assessed in relation to increased knowledge and skill sets using checklist evaluations and questionnaires, the results of which informed the design of a final seven-day training programme held in December 2013. A follow up of trained teachers was carried out in July 2014 following 7 months of routine implementation. A total of 15 teachers were evaluated at four stages: pilot training, two weeks following pilot, final training and seven months following final training.

Results: A total of 15 and 92 teachers were trained at the pilot and final training respectively. An average of $93 \%$ of the total steps required to use RDTs were completed correctly at the final training, declining to $87 \%$ after 7 months. All teachers were observed correctly undertaking safe blood collection and handling, accurate RDT interpretation, and correct dispensing of ACT. The most commonly observed errors were a failure to wait 20 minutes before reading the test result, and adding an incorrect volume of buffer to the test cassette.

Conclusion: Following training, teachers are able to competently use RDTs and ACTs test and treat children at school for uncomplicated malaria safely and accurately. Teachers demonstrate a comparable level of RDT use relative to non-health professional users of RDTs, and sustain this competency over a period of seven months during routine implementation.

\footnotetext{
* Correspondence: stefan.witek-mcmanus@lshtm.ac.uk

${ }^{1}$ Save the Children International, Zomba, Malawi

${ }^{2}$ Faculty of Infectious and Tropical Diseases, London School of Hygiene \&

Tropical Medicine, London, UK

Full list of author information is available at the end of the article
}

\section{() Biomed Central}

(c) 2015 Witek-McManus et al. Open Access This article is distributed under the terms of the Creative Commons Attribution 4.0 International License (http://creativecommons.org/licenses/by/4.0/), which permits unrestricted use, distribution, and reproduction in any medium, provided you give appropriate credit to the original author(s) and the source, provide a link to the Creative Commons license, and indicate if changes were made. The Creative Commons Public Domain Dedication waiver (http://creativecommons.org/publicdomain/zero/1.0/) applies to the data made available in this article, unless otherwise stated. 


\section{Background}

In the treatment of malaria, the World Health Organization (WHO) recommends parasitological confirmation prior to administration of anti-malarial drugs [1]. Malaria rapid diagnostic tests (RDTs) provide a reliable and practical means to provide diagnosis and are now routinely used by health workers [2]. There is increasing effort in incorporating RDTs across a wider spectrum of providers [3], embracing community health workers as part of community case management of malaria [4-6], and in both the formal and informal private sector [7-9]. As consequence, there has been recent interest in training community health workers $(\mathrm{CHW})$ to use RDTs [10] and in introducing RDTs at private drug shops [11]. Previous studies have shown that CHWs can accurately use RDTs after receiving training and a set of pictorial instructions [6, 12-14] and that this competence is retained over 12 months [15]. However, some reservations remain regarding the use of RDTs by non-health professionals due to concerns about blood safety, ability to interpret the test results correctly, and inappropriate use of ACTs [16, 17].

Malaria among school-aged children is increasingly being recognised as an important public health challenge [18-21], yet geographical and financial barriers that prevent school-aged children from obtaining prompt access to diagnosis and effective treatment remain [22-24]. Notably, recent evidence from Malawi has reported school-aged children to be at higher risk of Plasmodium infection than younger children, while also less likely to be brought for any type of malaria treatment [25]. Malawi has previously deployed school-based first aid kits (known as "Pupil Treatment Kits" or "PTKs") to provide immediate treatment for common health problems, including presumptive diagnosis and treatment of malaria using SP. One aim of the PTK was to reduce absenteeism attributable to malaria by providing prompt treatment at school, demonstrated by a reduction in overall and malaria-specific mortality [26] and decreased absenteeism and grade repetition [27]. Previous first-line treatments, such as chloroquine or sulphadoxinepyramethamine, did not require parasitological diagnosis and highlighted the feasibility and effectiveness of training of teachers to provide presumptive treatment [28, 29]. However, the introduction of artemisinin-based combination therapy (ACTs) in the country and the associated need for parasitological diagnosis led to the withdrawal of SP from PTKs shortly after beginning national rollout in 2008. The expanded use of RDTs by non-health professionals provides the opportunity to revisit the role that teachers can play in the diagnosis and treatment of uncomplicated malaria.

This paper documents the process of training primary school teachers in southern Malawi to use a first aid kit (hereby referred to as a "Learner Treatment
Kit" or "LTK") containing malaria RDTs and ACT for the diagnosis and treatment of uncomplicated malaria in primary school children. The LTK is currently the subject of a broader cluster randomised trial across 58 primary schools within TA Chikowi investigating the effectiveness, cost-effectiveness and feasibility of such an intervention (ClinicalTrials.gov: NCT02213211). As part of this trial, an evaluation of the LTK training was undertaken to assess whether trained teachers could accurately and safely use RDTs and provide appropriate treatment with $\mathrm{ACT}$, and whether this competence was retained up to 7 months after training during routine implementation.

\section{Methods}

\section{Study context}

A school-based programme of malaria diagnosis and treatment is currently being implemented by the Ministry of Health $(\mathrm{MoH})$, Ministry of Education, Science \& Technology (MoEST) and Save the Children. Between 2000 and 2007, a School Health and Nutrition (SHN) programme was implemented in primary schools in Mangochi district, where malaria was presumptively treated by teachers for malaria using sulphadoxine pyrimethamine (SP). Approximately 11,000 children across 100 primary schools were treated for uncomplicated malaria over the course of each year until the withdrawal of SP as first line treatment of uncomplicated malaria in 2008.

Since 2012, Save the Children has been collaborating with the district health and education authorities encompassing the Traditional Authority (TA) Chikowi in Zomba District in southern Malawi, including initiatives to investigate the burden of malaria in school children and potential approaches for its control. TA Chikowi is a rural, malaria endemic area [30]. Net primary school enrolment was estimated to be $87 \%$ as of 2007 [31]. School surveys conducted in 50 schools in 2011 revealed that $60 \%$ of children were infected with Plasmodium falciparum malaria parasites and $32 \%$ were anaemic [Mathanga et al. 2015, in press]. This survey also found that $38 \%$ of school children report usually sleeping under any type of mosquito net, although this may have increased following a subsequent national long lasting insecticidal net (LLIN) distribution campaign targeting at all age groups conducted by the NMCP in 2012. Awareness of this burden ultimately led the NMCP of Malawi, in discussion with the MoEST and Save the Children to consider reintroducing the PTK (now renamed as LTK). Since 2008, WHO guidelines recommend parasitological confirmation of all suspected cases of malaria prior to antimalarial treatment [1] and as such, LTKs would now be required to incorporate both RDTs and ACTs. This 
programme complements the current piloting of RDTs for community case management (CCM) of malaria in children under 5 years by health surveillance assistants in Malawi.

\section{Learner Treatment Kit}

The Learner Treatment Kit is a simple first aid kit, intended to be available to all primary school children (approximate age range 4-18 years) during school hours for the management of basic health problems, including uncomplicated malaria. At each school, between two and four trained teachers (called LTK dispensers) received seven days training in the use of the LTK, followed by a three-day mentorship period at a local health centre, as well as on-going support from the implementing partner. Alongside RDTs and ACTs, the LTK includes a limited selection of basic supplies including oral rehydration salts, tetracycline ointment, paracetamol and wound and burn dressings, as well as malaria-testing specific materials (e.g. sharps bin) and general items (e.g. gloves, weighing scales, waste bin). The LTK box is a double locked wooden box, kept in a locked room in the school to which only trained LTK dispensers have keys to access the contents. Non-sharps biowaste is burned on school grounds and sharps biowaste is disposed of in specially constructed locked pit latrines used solely for this purpose.

The LTK programme aims to encourage prompt treatment seeking by school children for any health problem at a place that is convenient, safe and acceptable. By improving the management of common health problems experienced by school children, such as malaria, the LTK is envisaged to reduce the number of days lost due to absenteeism from school. All services of the LTK are provided free of charge. In the event of any complicated or urgent health complaint, school children are immediately referred to a local health centre. LTK dispensers do not directly accompany the child to the health centre, but will call for a caregiver and explain why they have referred the child.

\section{Development of training materials and programme}

A likely difference between training health workers to use RDTs and training teachers is that the former have familiarity with general healthcare principles, including biosafety. It was therefore considered essential to develop a comprehensive and skill-focused training that would enable teachers to use RDTs and ACTs safely and accurately. The design of the training and production of associated materials was developed through a series of meetings held between June 2012 to July 2013 by a technical working group comprised of national, regional and district level parties from $\mathrm{MoH}$ and MoEST, with support from Save the
Children, College of Medicine - University of Malawi and London School of Hygiene \& Tropical Medicine. The basis of the LTK manual and training materials was current MoEST national school health curriculum, which includes a brief training for teachers in general issues relating to school child health and nutrition and is intended to complement the availability of basic school first aid kit. With the inclusion of RDT and ACTs, community case management documents used by $\mathrm{MoH}$ were incorporated. These materials were then refined in specific aspects of the LTK by incorporating relevant aspects of archive documents (e.g., manual from the implementation of the first generation of PTKs), contemporary training materials developed by the ACT Consortium for the training shop-keepers and community health workers in the use of RDTs in Uganda [48], and illustrated job-aids developed for use by community health workers developed by WHO [32]. The final LTK training materials are outlined in Table 1 and the full material can be accessed from [http://www.thiswormyworld.org/learner-treatment-kitproject].

\section{Training of teachers}

A pilot training was conducted in July 2013 with 15 teachers from five purposively selected primary schools lying outside of TA Chikowi (the ultimate implementation area). The head teacher of each school was asked to identify one male and one female teacher to participate

Table 1 Outputs of technical working group

\begin{tabular}{|c|c|}
\hline Document & Description \\
\hline Teachers' manual & $\begin{array}{l}\text { Illustrated manual containing all information } \\
\text { pertaining to the LTK, including guide to basic } \\
\text { health problems, use and } \\
\text { management of supplies, and record-keeping. }\end{array}$ \\
\hline Illustrated job-aids & $\begin{array}{l}\text { Five job aids designed to support LTK dispensers } \\
\text { in (1) criteria for using an RDT (2) danger signs } \\
\text { (symptoms) requiring referral to health centres } \\
\text { (3) how to conduct an RDT (4) interpreting } \\
\text { RDT results (5) treatment regimens for AL, } \\
\text { paracetamol and ORS. }\end{array}$ \\
\hline Treatment register & $\begin{array}{l}\text { Based on design of village health clinic registers } \\
\text { as currently used in Malawi, completed for every } \\
\text { learner consulted by the LTK dispenser. }\end{array}$ \\
\hline $\begin{array}{l}\text { Monthly reporting } \\
\text { form }\end{array}$ & $\begin{array}{l}\text { As required by district health office for monthly } \\
\text { reporting; outlining summaries of health problems } \\
\text { seen, treatments given and consumption of supplies. }\end{array}$ \\
\hline Stock order form & $\begin{array}{l}\text { Completed by LTK dispensers when requesting } \\
\text { supplies from a dispensing health centre. }\end{array}$ \\
\hline Referral form & $\begin{array}{l}\text { For the referral of all learners displaying } \\
\text { complicated or emergency 'signs' that are } \\
\text { not managed using the LTK. }\end{array}$ \\
\hline $\begin{array}{l}\text { Treatment } \\
\text { information forms }\end{array}$ & $\begin{array}{l}\text { To support verbal instructions given to learner; } \\
\text { information sheet translated into main local } \\
\text { language to explain symptoms observed and } \\
\text { management and/or advice given. }\end{array}$ \\
\hline
\end{tabular}


in the training. Participants were invited to attend a residential 4.5 day training (including a half-day evaluation) on the use of the LTK. The training was delivered by four facilitators from the District Health Office (DHO), all of whom had previously participated in training health workers in the management of malaria based on the use of RDTs. During the pilot training, 14 hours (h) were spent on the diagnosis and management of malaria across the four days, with introduction to malaria and its control $(1.5 \mathrm{~h})$, steps in diagnosis and treatment of malaria $(4 \mathrm{~h})$, practical demonstration of RDT use $(3 \mathrm{~h})$, RDT practice by the teachers $(3.5 \mathrm{~h})$ and completing the treatment documentation $(2 \mathrm{~h})$. An evaluation of the pilot training was used to inform the final design of the training programme.

On the basis of the results of the pilot training evaluation, four key modifications were made to the structure of the training programme: (i) increased training hours in practice of conducting RDTs, (ii) a day-long field visit (under facilitator supervision) for teachers to experience conducting malaria testing and treatment in the school environment, (iii) increased training hours in treatment of malaria, including documentation, and (iv) additional emphasis and practice in recognising danger signs and the process of referral. This increased the total length of the training workshop from four and a half to seven days. Schools were advised to select teachers below the age of fifty years for the training, with the exception of the head teacher who regardless of age was trained to act as a supervisor. On completion of training, teachers were required to complete a three day mentorship period at their local health facility to observe RDTs being conducted on patients who required testing for malaria.

The final training consisted of the following components: (i) introduction to the learner treatment kit $(3 \mathrm{~h})$, (ii) introduction to malaria and its control ( $3 \mathrm{~h}$ ) (iii) steps involved in the diagnosis and treatment of malaria $(3 \mathrm{~h})$, (iv) practical demonstration on conducting an RDT (3 h), (v) practice in the use of an RDT (12 h, including a oneday field visit to a study primary school), (vi) management of (non-malaria) minor illnesses and injuries (6 h) and (vii) treatment decisions and record keeping (4 h).

The final programme training was conducted in two phases during November and December 2013. In 28 randomly selected primary schools in TA Chikowi, 2 or 3 teachers (depending on school enrolment) plus the head teacher were invited to attend training to be a LTK dispenser, using criteria established by the District Education Office for the selection of teachers to carry out SHN activities. In total, 92 teachers attended a 7 day training programme (Table 2), delivered by thirteen facilitators from national, zonal and district health offices; including three who had attended the pilot training. Teachers were invited to attend one of two identical training sessions with no more than 50 teachers per session, shared equally across two separate classrooms. Facilitator's time was generally split between the two classrooms, moving between depending on teaching topic.

\section{Evaluation of training}

After both the pilot training and the main programme training, 15 teachers were assessed in their ability to conduct RDT procedures safely and accurately, and to interpret test results accurately. At the pilot training all teachers participated in the evaluation, whereas a sample of 15 teachers from all final training participants were randomly selected for evaluation. Teachers' ability to conduct test procedures safely and accurately was assessed using a 26 item checklist of steps included in test use, adapted from previous evaluations of RDT use [10, 12, 15, 33-36]. Each individual step was classified as being completed correctly (i.e. as described), incorrectly or not at all. For the purpose of analysis, the results of each checklist were further grouped into steps considered to be necessary to conduct an RDT safely (steps 3, 8, 10, 12 and 16) and accurately (steps 14, 15, 17, 18, 20a/20b and 21) as similarly described by Counihan et al. [15] (Table 3). Teacher's ability to interpret RDTs accurately was assessed using a printed sheet of five RDTs of differing results [37]. The ability to give appropriate treatment was assessed using a short case-scenario where teachers were required to select the appropriate treatment dose and complete the learner treatment register and parent information sheet based on a positive RDT result, weight and age of the child, and reported minor symptoms. Finally, a self-administered questionnaire recorded personal and professional characteristics of the teachers.

Two weeks after the pilot training, teachers were reevaluated using the same checklist to assess retention of skills in using RDTs. Seven months following the final programme trained teachers were followed up during routine visits to schools to assess whether safety and accuracy remained adequate over time. This evaluation was conducted in-situ, with teachers observed at their school testing a child who had sought assistance on that day.

Teachers at the pilot training were further required to complete a script concordance test (SCT) consisting of a short clinical vignette, following which the teacher was presented with at least two independent hypotheses, each with an associated 'new' piece of information that they were required to interpret [38]. The teacher was required to judge the effect of this new information using a five-point Likert scale against the original diagnostic hypothesis. The similarity, or concordance, of this response was then measured against that of a panel of experts (in this case, the training facilitators) whose responses were aggregated [39]. For the purpose of evaluation, this SCT was restricted to ten diagnostic or 
Table 2 Demographic and professional characteristics of pilot training and final training participants

\begin{tabular}{|c|c|c|c|c|}
\hline \multirow{3}{*}{ Characteristic: } & \multicolumn{4}{|l|}{$\%$, median or mean (range) } \\
\hline & \multirow{2}{*}{$\begin{array}{l}\text { Pilot training participants and } \\
\text { evaluation sample }(n=15)\end{array}$} & \multicolumn{3}{|l|}{ Final training } \\
\hline & & $\begin{array}{l}\text { All participants } \\
(n=92)\end{array}$ & $\begin{array}{l}\text { End of training evaluation } \\
\text { sample }(n=15)\end{array}$ & $\begin{array}{l}7 \text { month follow-up } \\
\text { sample }(n=15)\end{array}$ \\
\hline Male (\%) & 60 & 68 & 67 & 80 \\
\hline Headteacher (\%) & 33 & 32 & 33 & 13 \\
\hline Median age (years): & $37(21-58)$ & $31(21-58)$ & $30(24-49)$ & $30(24-45)$ \\
\hline Median length of employment(years): & $4(0.5-33)$ & $4(0.75-35)$ & $4(1.5-24)$ & $1.5(1.5-24)$ \\
\hline$>5$ years' experience (\%): & 47 & 38 & 53 & 27 \\
\hline \multicolumn{5}{|l|}{ Classes currently taught (\%): } \\
\hline None & 13 & 0 & 0 & 0 \\
\hline Standard 1-4 & 13 & 40 & 43 & 40 \\
\hline Standard 5-8 & 80 & 64 & 64 & 67 \\
\hline \multicolumn{5}{|l|}{ Subjects taught (\%): } \\
\hline Life Skills & 66 & 55 & 38 & 47 \\
\hline English & 66 & 57 & 38 & 47 \\
\hline Science & 40 & 30 & 38 & 27 \\
\hline Mathematics & 40 & 69 & 64 & 73 \\
\hline
\end{tabular}

treatment scenarios with two or three potential hypotheses. A previously proposed method of assessment was used to interpret scores, whereby the scores of the teachers were interpreted based on the number of standard deviations from the mean score given by the panel of experts [40]. Results were considered acceptable if they were within four standard deviations of the mean of the expert panel, based on a previously described threshold [41].

Finally, perceptions and opinions of the pilot training workshop agenda, presentations and materials were assessed through focus group discussions and selfadministered questionnaires completed by the teachers and semi-structured interviews also took place with three of the facilitators. Topics of discussion were divided into two areas: the training programme as a whole, and training specific to use of RDTs.

\section{Data analysis}

Results of evaluation checklists and script-concordance tests were collated, inputted into Excel 2013 (Microsoft, Redmond, WA) and analysed using Stata 13 (Statacorp, College Station, TX). The percentage of steps performed correctly after the final training and seven months later, and differences in the proportions of teachers completing the RDT safely or accurately were analysed using Fishers's exact test. Due to a priori concerns over the age of teachers trained to become LTK dispensers, further analysis was conducted on the pilot training results comparing the results between two age groups, divided along the median pilot training participant age (37 years).
The results of the SCT conducted in the pilot training was analysed using the Mann-Witney $U$ test. The internal consistency of the SCT was acceptable (Cronbach's $\alpha=0.76$ ). Differences in the demographic characteristics of each evaluation sample were assessed by Kruskal-Wallis test.

Focus group discussions and individual interviews conducted were transcribed and managed using Nvivo 10 (QSR International Pty Ltd, Australia). Coding took place collectively across all qualitative data sources to identify key themes, both within and across different data collection tools. Data were thematically analysed to describe experiences of the pilot training programme from both participant and facilitators perspectives, and were interpreted in the context of the results of the other evaluation tools.

\section{Ethical approval}

The study was approved by the National Health Sciences Research Committee (NHSRC) Malawi (IRB No. 1057) and the London School of Hygiene \& Tropical Medicine Ethics Committee (6432). Prior to the start of the study, sensitization meetings were held with teachers, parents, school management committees and traditional authorities. Following invitation of individual teachers to attend training by the District Education Office SHN Coordinator, an overview of the training, and risks and benefits of participation, were explained by the facilitation team and printed information sheets were provided to teachers to review. Written informed consent was obtained from all selected 
Table 3 Analysis of RDT use and treatment scenario steps (i) following completion of pilot training and (ii) 2 weeks after pilot training, by individual step

\begin{tabular}{|c|c|c|c|c|c|}
\hline \multirow{2}{*}{\multicolumn{2}{|c|}{ \# }} & \multirow[b]{2}{*}{ Description of step } & \multicolumn{2}{|c|}{$\begin{array}{l}\text { (\% completing step correctly) } \\
(n=15)\end{array}$} & \multirow[b]{2}{*}{ Common error(s) } \\
\hline & & & End of training & 2 weeks post training & \\
\hline 1 & & Work surface disinfected with alcohol & 100 & 93 & \\
\hline 2 & & Assembles all required equipment & 47 & 87 & Lack of preparation of items before conducting RDT \\
\hline 3 & $S$ & Put on new pair of gloves & 100 & 100 & \\
\hline 4 & & Check expiry date of RDT packet & 80 & 73 & Skipped \\
\hline 5 & & Check desiccant sachet is dry & 40 & 66 & Skipped \\
\hline 6 & & Write client name on cassette & 100 & 100 & \\
\hline 7 & & Place cassette on level surface & 100 & 100 & \\
\hline 8 & $\mathrm{~S}$ & Clean finger with alcohol swab & 93 & 100 & \\
\hline 9 & & Allow finger to dry before pricking & 100 & 100 & \\
\hline 10 & $S$ & Use sterile lancet to prick finger & 93 & 93 & $\begin{array}{l}\text { Set down sterile lancet onto work surface after } \\
\text { removing cap }\end{array}$ \\
\hline 11 & & Puncture side of ball of the $3 \mathrm{rd}$ or 4 th finger & 93 & 100 & \\
\hline 12 & $S$ & $\begin{array}{l}\text { Dispose of lancet immediately after pricking } \\
\text { finger }\end{array}$ & 87 & 100 & Used lancet, then set down onto work surface \\
\hline 13 & & Wipes away initial blood from finger & 93 & 93 & \\
\hline 14 & A & Uses blood collection device correctly & 73 & 100 & $\begin{array}{l}\text { Attempted to 'scoop' blood, inadequate volume } \\
\text { of blood }\end{array}$ \\
\hline 15 & A & Correctly transfer blood to cassette using tool & 93 & 100 & \\
\hline 16 & $S$ & Dispose of blood collection tool immediately & 100 & 100 & \\
\hline 17 & A & Dispenses correct volume of buffer & 93 & 93 & \\
\hline 18 & A & $\begin{array}{l}\text { Start the timer immediately after adding } \\
\text { buffer }\end{array}$ & 60 & 66 & $\begin{array}{l}\text { Started timer before adding buffer or after clearing } \\
\text { workspace }\end{array}$ \\
\hline 19 & & Dispose of non-sharps safely & 100 & 100 & \\
\hline 20 & A & $\begin{array}{l}\text { State the correct time that the RDT can be } \\
\text { read }\end{array}$ & 80 & 87 & Stated "15 to 20 " or "20 minutes" \\
\hline 21 & A & Reads test results correctly (RDT test sheet) & 53 & 87 & Misidentified faint positive as negative or invalid. \\
\hline 22 & $T$ & Completes correct sections of treatment register & 87 & & Not completed \\
\hline 23 & $T$ & Selects appropriate AL dose based on weight & 60 & & Ticks "LA x 1 tab" on treatment register \\
\hline 24 & T & Selects appropriate paracetamol dose & 60 & & Not completed; prescribes incorrect dose \\
\hline 25 & $T$ & $\begin{array}{l}\text { Selects correct Parent Information sheet for AL } \\
\text { dose }\end{array}$ & 13 & & Uses LA x 1 Parent Information Sheet \\
\hline 26 & $T$ & $\begin{array}{l}\text { States correct time for } 2 \text { nd dose of AL to be } \\
\text { taken }\end{array}$ & 40 & & $\begin{array}{l}\text { Not completed; instructed } 2 \text { nd dose to be taken } \\
\text { after } 6 \text { hours }\end{array}$ \\
\hline
\end{tabular}

$S$ steps relating to safety of conducting test, $A$ steps relating to accuracy of conducting test, $T$ steps relating to treatment of uncomplicated malaria

teachers before the beginning of both the pilot and the final programme training.

\section{Results}

A total of 15 teachers participated in the pilot training and 92 teachers participated in the final training (Table 2), representing a wide range of ages and professional experience. In the final training, $67 \%(n=62)$ of participants were male and teachers were on average aged 30 years (head teachers 46 years). There were no significant differences in the characteristics of the sample of teachers evaluated as part of the pilot training, final training or at seven month follow-up (Table 2).

\section{Pilot training}

Table 3 details the proportion of teachers who completed each test step correctly during the pilot training and reports the most common errors. On average, teachers 


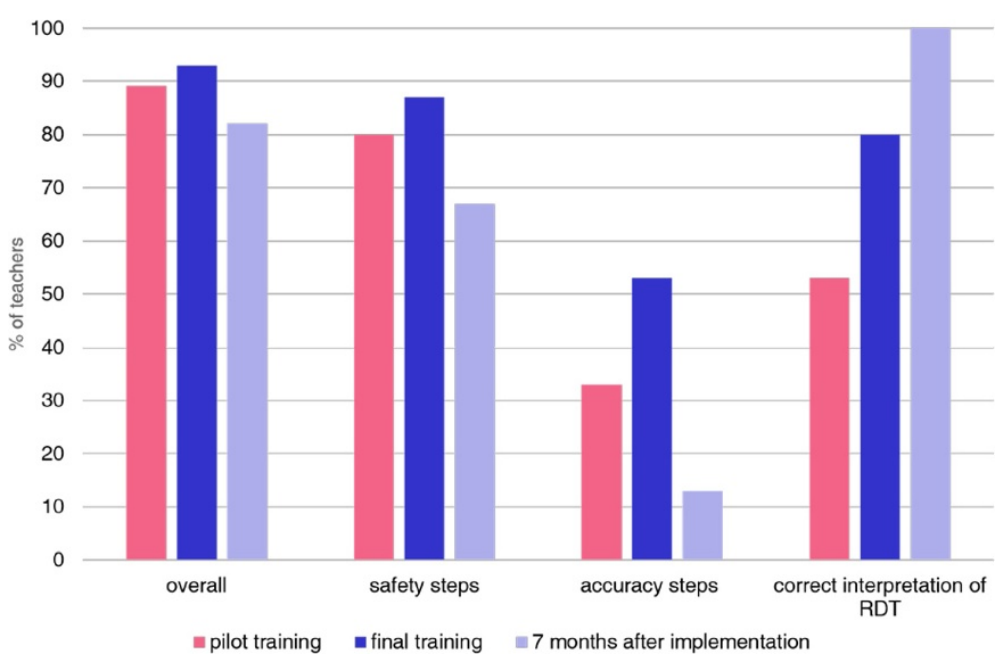

Fig. 1 Percentage of teachers correctly completing (i) all RDT usage steps, (ii) all RDT steps defined as safe use (iii) all RDT steps defined as accurate use (iv) correct interpretation of RDT result

completed $89 \%$ (standard deviation (sd) =1.54) of steps involved in the use of an RDT correctly (steps 1-21), with an average $2.33(\mathrm{sd}=1.53)$ steps performed incorrectly and 0.93 ( $\mathrm{sd}=0.96)$ steps missed. The steps most frequently completed incorrectly were to check if the desiccant sachet was dry (step 5, $40 \%$ incorrect) and to assemble all required equipment before beginning the RDT (step 2, $47 \%$ incorrect). A total of $53 \%$ of teachers identified all RDT results correctly (step 21), with the most common mistake misidentification of a faint positive or a negative result as invalid (Fig. 1).

While all teachers aged $<37$ years conducted all steps defined as safe use of RDTs, only $58 \%$ of teachers aged $\geq 37$ years did so $(p=0.07)$, with the most common error being placing the lancet down following use prior to disposal rather than immediate disposal of the lancet into the sharps container (step 12). There was no evidence to suggest that successful completion of all steps required to perform the RDT accurately differed significantly by age group (38 vs. $14 \%, p=0.57$ ). However, correct reading of RDT results (step 21) was found to vary significantly between age groups (88 vs. $14 \%, p=0.01$ ), with teachers aged $<37$ years performing better. The frequency of the other four most common errors did not vary significantly between age groups.

An average of $50 \%$ of the five steps (step 21-26) associated with selection of appropriate treatment and correct completion of the treatment forms were completed correctly (Table 3). While $87 \%$ of teachers completed the treatment register correctly, $60 \%$ of teachers selected the appropriate artemether-lumefantrine (AL) and paracetamol doses for the child (frequently indicating in the treatment register the selection of a lower than required AL dosage) and only $13 \%$ of teachers selected the correct parent information sheet for the AL dose required. Furthermore, less than half of the teachers stated the correct time for the second dose to be taken by the child (i.e., $8 \mathrm{~h}$ after the first dose).

Two weeks following training, the percentage of teachers correctly performing each step was the same or greater (Table 3). The most notable improvements observed were assembling the equipment prior to testing (step 1) $(+40 \%$; $p=0.05)$ correctly interpreting the RDT result (step 21) (+35\%; $p=0.109)$. Checking the desiccant sachet (step 5, 66 \%) and starting the timer immediately after adding buffer (step 18, $66 \%$ ) remained the two most commonly incorrectly completed steps at both assessments.

When considering the ability of teachers to make appropriate clinical decisions (e.g., following a certain RDT result, the likelihood of a suggested diagnosis or suitability of a proposed treatment) compared to that of a hypothesised expert group (here represented by the facilitators) by SCT, there was strong evidence of a significant difference between the results of the two groups $(p<0.01)$. The mean SCT score for the expert panel was $88.4 / 100(\mathrm{sd}=7.5)$ and $55.8 / 100(\mathrm{sd}=14.9)$ for the teachers. In total, $47 \%(n=7)$ of participants were within four standard deviations of the expert panel mean score (Fig. 2).

\section{Perceptions of the pilot training by participants and facilitators}

Teachers commonly praised the sessions where they were required to practice using an RDT as by far the most enjoyable or interesting component of the training programme. However, a lack of sufficient practical sessions was one of the most commonly described 


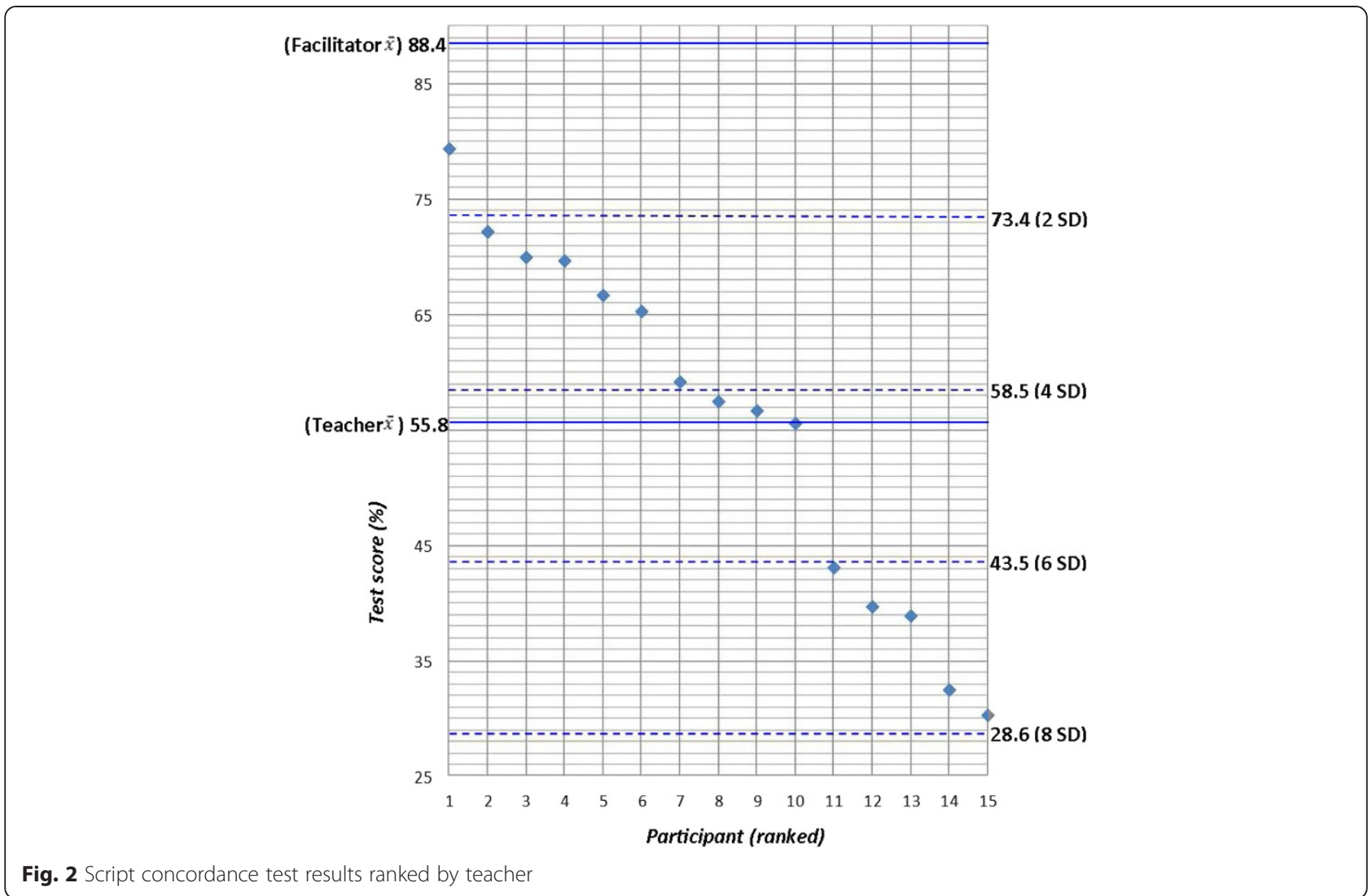

deficiencies of the pilot training by both facilitators and teachers, and perceived as key to improving both competence and confidence in the use of an RDT. All facilitators suggested that these practical sessions could have greater value if held in the programmatic setting.

Others will also be very confident if they would change the time to have more practice. So if they are going to have more practice, all of them will be very confident. Teacher 8, FGD 2.

For them, practicing amongst themselves because they are all adults, it was somehow easier. They need to experience it with children, so they can learn how they can handle some children trying to run away and whatever, because this will be the real situation at their schools. Facilitator 1.

The pilot training programme was considered to have been clear, relevant, and suitable to the background of participants. All facilitators commented on the fact that unlike previous RDT trainings that they had been involved in, this was the first where 'non-medical' professionals, with a different level of pre-existing knowledge and experiences, were being trained. All facilitators described training teachers as relatively more difficult to do as a result of a lack of both experience and confidence in carrying out "medical procedures":

It was a crucial component to bring them to the medical background part and make them understand what we really want to do... it was very easy to do the other training as compared to this teacher training. Facilitator 2.

One facilitator, while still appreciating that this lack of familiarity made some aspects of training more difficult, suggested that it could actually improve the overall quality of the training programme. He described how the engagement of healthcare workers had been worse in previous trainings compared to that of the teachers, due to their greater familiarity with some of the concepts.

This time when we were rolling out the rapid diagnostic tests [in health surveillance assistants] it was like a repeat, so people had some knowledge, the concentration was a little bit less because they had some knowledge. Facilitator 3.

The majority of teachers (80\%) reported themselves as feeling 'very confident' in either the use of an RDT or 
treating for malaria in an anonymous post-training evaluation questionnaire. A smaller proportion (53 \%) reported the same level of confidence in recognising 'danger signs' of malaria. Facilitators generally considered the training to have been successful in equipping participants with the necessary skills to manage minor illnesses and injuries competently. While acknowledging that it had not been the aim of the training programme to go beyond the referral of complicated illnesses, some reservations remained over the competency of teachers in this regard, echoing concerns implied by teachers' lower reported level of confidence.

\section{It should be adequate, to manage minor illnesses at school. Because we are emphasizing the minor element, so it should be enough. Facilitator 3.}

\section{Final training}

Following completion of the final training, teachers completed an average of $93 \%(19.5 / 21)$ of RDT steps correctly (Table 4 ), a $4 \%$ increase from the pilot training. With the exception of step 4 (checking the expiry date of the RDT) each step was correctly carried out by $\geq 80 \%$ of teachers. When considered by steps necessary for safe or accurate use, $87 \%$ of teachers completed the RDT safely and $53 \%$ completed the RDT accurately (Fig. 1). With the exception of step 4, no individual safety or accuracy specific step was completed incorrectly by more than two teachers. A total of $80 \%$ of teachers interpreted all RDT results correctly, a large but nonsignificant improvement from the pilot training $(p=0.25)$.

Provision of correct treatment (as assessed by case scenario) was observed to have improved when compared to the pilot training, most significantly in selection of the correct parent information sheet (step 25, 54\% increase, $p=0.007$ ) but to a lesser extent also in selecting the correct dose of $\mathrm{AL}$ (step 23, $27 \%$ increase, $p=0.11$ ).

Following 7 months of LTK programme implementation, an average of $82 \%$ of RDT steps were completed correctly (Table 4). The only step that significantly declined in correct completion was the proportion of teachers who checked whether the desiccant sachet inside the cassette packet was dry $(33 \%$ decrease, $p=$ 0.04). When compared to the end of training, a higher proportion of teachers were observed checking the expiry date of the RDT (step 4, $13 \%$ increase) and writing the child's name on the cassette (step 6, $13 \%$ ). Declines in completion of individual steps were observed in the proportion of teachers correctly (i.e., to the side of the finger tip) puncturing the finger (step 11, $27 \%$ decrease), dispensing correct volume of buffer (step $17,27 \%$ decrease) and starting the timer immediately after adding buffer (step 18, 27 \% decrease). Only seven individual mistakes were recorded within a total of 75 safety steps conducted by the fifteen teachers at the seven month follow-up, and only two teachers failed on more than one safety component step (Table 5). Despite all participants correctly stating the correct length of time to wait before reading the result of an RDT and reading the RDT results correctly, only $27 \%$ of teachers were observed waiting the correct length of time before reading the RDT result (Step 20b).

Notably improving relative to both the pilot and final trainings, all teachers after 7 months selected the correct dose of AL treatment, and all except one teacher provided the correct dosage of paracetamol (Table 4). While all teachers were observed providing instructions verbally on taking $\mathrm{AL}, 60 \%$ of teachers did not provide the parent information sheet with correctly completed instructions (step 25 \& 26). A significant increase in the percentage of teachers selecting the correct dosage of paracetamol by weight was observed $(+33 \%, p=0.014)$ with no significant decline in any other treatment step.

\section{Discussion}

This study reports the first known example of teachers being trained in the use of RDTs and identifies several important issues for the implementation of a programme involving the use of teachers to provide diagnosis and treatment of malaria in school children. While teachers were able to correctly carry out the majority of steps required to complete an RDT following a seven day training, and maintain this over the following seven months, there are specific areas - particularly the final steps of adding buffer solution, waiting the required length of time before reading, and some aspects of treatment administration that have implications for monitoring of RDT use by teachers and future training involving similar participants.

While challenging to compare directly between studies owing to the variability of different RDT products and evaluation checklists used, the results of this study compare favourably with the findings of previous evaluations of RDT use following training, suggesting a similar level of competency in RDT use demonstrated by teachers compared to other RDT users when compared by the proportion of RDT steps completed correctly. An assessment of rural CHWs in Laos described an average of $78 \%$ of steps involved in RDT use performed correctly with the use of a job aid plus one hour orientation [33], with two of the most common errors similarly relating to incorrect time waited before reading of the RDT result and a failure to check the condition of the desiccant sachet. Similar studies describe correct completion of all steps in the use of an RDT by 80 and $54 \%$ of CHWs in Uganda respectively following a one-day training $[10,42]$. The former of these studies again reported incorrect time waited before reading RDT results and 
Table 4 Analysis of RDT use and learner treatment scenario steps (i) following completion of final training and (ii) 7 months after final training, by individual step

\begin{tabular}{|c|c|c|c|c|c|}
\hline & & & (\% completing s & correctly) $(n=15)$ & \\
\hline & & Description of step & End of training ${ }^{a}$ & $\begin{array}{l}7 \text { months post } \\
\text { training }^{b}\end{array}$ & Most common error(s) \\
\hline 1 & & Work surface disinfected with alcohol & - & - & Not applicable due to change in training protocol. \\
\hline 2 & & Assembles all required equipment & 87 & 100 & \\
\hline 3 & S & Put on new pair of gloves & 93 & 93 & \\
\hline 4 & & Check expiry date of RDT packet & 67 & 80 & Did not check. \\
\hline 5 & & Check desiccant sachet is dry & 100 & 67 & Did not check. \\
\hline 6 & & Write client name on cassette & 80 & 93 & \\
\hline 7 & & Place cassette on level surface & 100 & 100 & \\
\hline 8 & $\mathrm{~S}$ & Clean finger with alcohol swab & 93 & 93 & \\
\hline 9 & & Allow finger to dry before pricking & 100 & 93 & \\
\hline 10 & $\mathrm{~S}$ & Use sterile lancet to prick finger & 93 & 93 & $\begin{array}{l}\text { Set down sterile lancet onto surface after } \\
\text { removing cap }\end{array}$ \\
\hline 11 & & $\begin{array}{l}\text { Puncture side of ball of the 3rd or 4th } \\
\text { finger }\end{array}$ & 100 & 73 & Punctured vertically (i.e. perpendicular to the tip) \\
\hline 12 & $\mathrm{~S}$ & $\begin{array}{l}\text { Dispose of lancet immediately after } \\
\text { pricking finger }\end{array}$ & 100 & 87 & Used lancet, then set down onto work surface \\
\hline 13 & & Wipes away initial blood from finger & 100 & 93 & \\
\hline 14 & A & Uses blood collection device correctly & 100 & 100 & \\
\hline 15 & A & $\begin{array}{l}\text { Correctly transfer blood to cassette using } \\
\text { tool }\end{array}$ & 100 & 100 & \\
\hline 16 & $\mathrm{~S}$ & $\begin{array}{l}\text { Dispose of blood collection tool } \\
\text { immediately }\end{array}$ & 100 & 87 & $\begin{array}{l}\text { Left blood collection device inserted into } \\
\text { sample well. }\end{array}$ \\
\hline 17 & A & Dispenses correct volume of buffer & 87 & 60 & Too much buffer added. \\
\hline 18 & A & $\begin{array}{l}\text { Start the timer immediately after adding } \\
\text { buffer }\end{array}$ & 87 & 60 & Did not record time. \\
\hline 19 & & Dispose of non-sharps safely & 93 & 100 & \\
\hline $20 a$ & A & $\begin{array}{l}\text { States the correct time to read RDT } \\
\text { (RDT test sheet) }\end{array}$ & 100 & - & \\
\hline $20 b$ & A & $\begin{array}{l}\text { Waits correct time before reading RDT } \\
\text { result }\end{array}$ & - & 27 & Waited $<5$ minutes before reading result. \\
\hline 21 & A & Reads test results correctly ${ }^{c}$ & 80 & 100 & \\
\hline 22 & $\mathrm{~T}$ & $\begin{array}{l}\text { Completes correct sections of treatment } \\
\text { register }\end{array}$ & 87 & 93 & \\
\hline 23 & $\mathrm{~T}$ & $\begin{array}{l}\text { Selects appropriate AL dose based on } \\
\text { weight }\end{array}$ & 87 & 100 & Did not record time. \\
\hline 24 & $\mathrm{~T}$ & Selects appropriate paracetamol dose & 60 & 93 & \\
\hline 25 & $\mathrm{~T}$ & $\begin{array}{l}\text { Selects correct Parent Information sheet } \\
\text { for AL dose }\end{array}$ & 67 & 40 & \\
\hline 26 & $\mathrm{~T}$ & $\begin{array}{l}\text { States correct time for } 2 \text { nd dose of AL to } \\
\text { be taken }\end{array}$ & 47 & 40 & $\begin{array}{l}\text { Did not complete information sheet, provided } \\
\text { counselling verbally only }\end{array}$ \\
\hline
\end{tabular}

abserved at training venue, ${ }^{b}$ observed at school, $S$ steps relating to safety of conducting test, $A$ steps relating to accuracy of test, $T$ steps relating to treatment of uncomplicated malaria ${ }^{\mathrm{C}}$ The RDT conducted was also read for the evaluation of this step at the 7 month follow-up in addition to the printed sheet of photographed RDT results used for the evaluation of this step at the end of training

both reference a similar common mistake relating to incorrect volume of buffer being added. While a study of $\mathrm{CHWs}$ has reported $90 \%$ of steps were correctly completed using a job aid following a three-hour training [12], correct completion of steps required for 'safe' and 'accurate' use of the RDT was observed in 92 and $95 \%$ of participants. In contrast, correctly completion of $>95 \%$ RDT steps has been observed among CHWs in the Democratic Republic of Congo [43] and Uganda [14]. Encouragingly, errors related to incorrect collection and transfer 
Table 5 Percentage of teachers correctly completing individual steps required to carry out an RDT (i) accurately or (ii) safely following final training and after 7 months after training

\begin{tabular}{lllll}
\hline & \multicolumn{4}{l}{$\begin{array}{l}\text { Percentage of teachers completing } \\
\text { number of steps correctly for }\end{array}$} \\
& \begin{tabular}{l} 
accurate or safe RDT use $(n=15)$ \\
\cline { 2 - 5 }
\end{tabular} steps & 4 steps & 5 steps & 6 steps \\
\hline Accuracy at end of training & 100 & 100 & 100 & 53 \\
Accuracy 7 months post training & 100 & 80 & 40 & $13^{\text {a }}$ \\
Safety at end of training & 100 & 93 & 87 & \\
Safety 7 months post training & 100 & 87 & 67
\end{tabular}

${ }^{a}$ Only 2 teachers were observed correctly completing step 20 (waiting 20 min before reading the RDT result)

of the blood sample, frequently reported in several of these previous evaluations were not observed in the present study.

The performance of teachers in this study over the seven months following training declined significantly in two areas - failure to check the status of desiccant sachet, and waiting a correct length of time before reading the RDT result. A six-month evaluation of Sudanese nurses and medical assistants similarly identified inappropriate length of time waited before reading the test, but also inadequate blood volume and improper positioning of the device to be the most frequently observed errors when using an RDT [34]. An assessment of routine use of RDTs by 25 experienced South African nurses and nursing assistants, while noting that $76 \%$ had only received 'in-house' training from their colleagues, specifically highlighted serious deficiencies in infection control aspects of RDT use, including failing to always use a new pair of gloves and disposal of the lancet immediately after pricking the finger [44]. In contrast, an assessment by Counihan et al. of Zambian CHWs at three month intervals following training observed high performance ( $87.5 \%$ of 'critical' steps performed correctly at three months) which was maintained over 12 months [15].

Areas of concern following the pilot training - notably, failure to read RDT results correctly and provide appropriate treatment - appear to have been resolved following modifications to the final training programme. However, new errors in the volume of buffer added to the RDT, timing of the RDT and early reading of the RDT result arose over the following 7 months. The two later steps likely reflect inevitable consequences of short (15-30 min) school breaktimes in which to carry out a relatively high number of RDTs, a notable difference to the routine of RDT use by CHWs that may be more spread out over the course of the day. Step 20 of the checklist evaluation used during the pilot and final training was modified for use at follow up, requiring those conducting an RDT to wait 20 min (rather than stating the time to be waited) before reading the test result, regardless of whether it was positive or negative. We note that this study held a relatively strict definition of this component step compared to previous evaluations of RDT administration, such as allowing reading of a positive RDT result as soon as the control strip has appeared [15]. By this definition, $87 \%$ of teachers would be considered to have correctly completed step 20 at the seven-month follow up.

The small evaluation sample size, while not unique to this specific study, restricts the power required to establish the significance of differences in performance. Furthermore, assessment in all but the last evaluation was observed in an artificial setting that simulated testing of a 'child' using another participant that may have biased performances. While the results of the SCT used in this study demonstrate its feasibility and potential usefulness in such a setting, several necessary concessions made in its design may have compromised its reliability. The SCT contained fewer cases than is usually accepted as required to achieve sufficient reliability [45] but still met the recommended one-hour length [46]. The size of the expert panel - restricted by the choice of facilitators as experts - was also smaller than required to achieve reliable scores [47], and the use of standard deviation to interpret scores has been criticised for its ultimately arbitrary nature [41]. The duration of training, and hence resources required, was considerably greater than previously reported trainings of RDT use owing to its incorporation into a larger first aid training programme. However, if conducted separately the RDT-specific component of this training would total approximately 2 full training days.

Through presenting the design, piloting, implementation and evaluation of a comprehensive training programme for teachers, our results further demonstrate the feasibility of training lay persons to manage uncomplicated malaria at community level using RDTs and ACTs. While this cohort of individuals is unique in taking on this task as a separate and additional responsibility, rather than change or modification to their primary role (such as in the case of healthcare workers or drugshop keepers), we are able to identify common challenges raised by previous investigations of RDT use in other groups. However, this additional role also raises a number of questions, including the best methods of ensuring sufficient competency in the use of RDTs and ACTs in the longer term, and the ability of teachers to balance this role alongside their teaching schedule. These issues are being further investigated through an ongoing evaluation of the impact, cost effectiveness and acceptability of the programme of school-based diagnosis and treatment of uncomplicated malaria. Although the evidence of teachers' ability to successfully carry out 
this role does not constitute an argument for replacing the functions of the formal health system, it does represent a novel and realistic opportunity to expand access to prompt diagnosis and treatment for school children within the context of a constrained health system.

\section{Conclusion}

School teachers with no experience of providing malaria case management can be trained to carry out malaria rapid diagnostic tests safely and accurately and provide appropriate treatment as part of a sevenday training in management of basic illnesses and injuries. This competency can be maintained for at least seven months following training when teachers are conducting regular consultations of children in a school setting. Further investigation will determine whether this competency can be retained long-term, and the most effective combination of supervision, retraining and support to achieve this.

\section{Competing interests}

The authors declare that they have no competing interests.

\section{Authors' contributions}

$D A, K E H, S J B, D P M$ and NR conceived of and designed the intervention. AV, $\mathrm{KEH}, \mathrm{DA}, J \mathrm{~S}, \mathrm{CM}, \mathrm{RM}, \mathrm{SN}, \mathrm{EP}, \mathrm{SW}-\mathrm{M}$, and DPM designed the training materials and were responsible for the outputs of the technical working group. SW-M, AM, EP, SN, TC and DM coordinated the training and implementation of the intervention. DA, JS and CM oversaw the training and supervised implementation of the intervention. SW-M, KEH, EP, SN and AM conducted the evaluations and contributed to data collection. SW-M, KEH and SJB drafted the manuscript. DPM, AV, AM, DM and NR contributed to the writing of the manuscript. All authors read and approved the final manuscript.

\section{Acknowledgements}

The authors are grateful to the teachers who participated in the trainings and evaluations, and who continue to implement the LTK programme with diligence and enthusiasm. We gratefully acknowledge the support of the Ministry of Health and Ministry of Education, Science \& Technology at national and district levels: Clifton Gondwe, Dubulayo Moyo, Pepsi Nangwale, Enock Chitembe, Scotch Santula, Dorothy Gunda Phiri, Timothy Phiri, Lameck Chilinda, Kesna Duwa, Dinna Rapozo, Bruno Gama, Treza Msikuwanga, Treza Nenula, Dorothy Moyo, Abraham Sineta, Gift Chinomba and also to Seminie Nyirenda at College of Medicine, University of Malawi. Thanks go to the staff of Save the Children in Malawi for their support during training and data collection, especially those at the Zomba Office: Prince Kasinja, Saulos Ngwira, Daisy Chitimbe, Ignatius Mabangwe, Paul Nguluwe, Peter Maudzu and lan Banda.

\section{Funding}

The study was funded by Save the Children Child Sponsorship and the International Initiative for Impact Evaluation (3ie). DPM is supported by the Cooperative Agreement Number 3U01CK000135 between the Center for Disease Control and Prevention and the University of Malawi, College of Medicine. SJB is supported by a Wellcome Trust Senior Fellowship in Basic Biomedical Science (098045). The opinions expressed herein are those of the authors and do not necessarily reflect the views of the funding agencies.

\section{Author details}

${ }^{1}$ Save the Children International, Zomba, Malawi. ${ }^{2}$ Faculty of Infectious and Tropical Diseases, London School of Hygiene \& Tropical Medicine, London, UK. ${ }^{3}$ Malaria Alert Centre, College of Medicine, University of Malawi, Blantyre, Malawi. ${ }^{4}$ National Malaria Control Programme, Ministry of Health, Lilongwe, Malawi. ${ }^{5}$ Health Technical Support Services-Diagnostics, Ministry of Health, Lilongwe, Malawi. ${ }^{6}$ Zomba District Health Office, Ministry of Health, Zomba,
Malawi. ${ }^{7}$ Department of School Health, Nutrition, HIV \& AIDS, Ministry of Education, Science \& Technology, Lilongwe, Malawi. ${ }^{8}$ Zomba District Education Office, Ministry of Education, Science \& Technology, Zomba, Malawi. ${ }^{9}$ Save the Children USA, Washington, DC, USA.

Received: 2 February 2015 Accepted: 4 September 2015 Published online: 17 September 2015

\section{References}

1. Malaria Case Management Operations Manual. WHO (World Health Organisation): Geneva, Switzerland. 2009. ISBN is 9789241598088.

2. Ruizendaal E, Dierickx S, Peeters Grietens K, Schallig H, Pagnoni F, Mens P. Success or failure of critical steps in community case management of malaria with rapid diagnostic tests: a systematic review. Malar J. 2014;13(1):229.

3. Kamal-Yanni MM, Potet J, Saunders PM. Scaling-up malaria treatment: a review of the performance of different providers. Malar J. 2012;11:414.

4. Ratsimbasoa A, Ravony H, Vonimpaisomihanta JA, Raherinjafy R, Jahevitra M, Rapelanoro R, et al. Management of uncomplicated malaria in febrile under five-year-old children by community health workers in Madagascar: reliability of malaria rapid diagnostic tests. Malar J. 2012;11:85.

5. Ohnmar T-M, San-Shwe T-W, Chongsuvivatwong V. Effects of malaria volunteer training on coverage and timeliness of diagnosis: a cluster randomized controlled trial in Myanmar. Malar J. 2012;11(1):309.

6. Mubi M, Janson A, Warsame M, Martensson A, Kallander K, Petzold MG, et al. Malaria rapid testing by community health workers is effective and safe for targeting malaria treatment: randomised cross-over trial in Tanzania. PLoS One. 2011;6(7):e19753.

7. Chandler CIR, Hall-Clifford R, Asaph T, Pascal M, Clarke S, Mbonye AK. Introducing malaria rapid diagnostic tests at registered drug shops in Uganda: Limitations of diagnostic testing in the reality of diagnosis. Soc Sci Med. 2011;72(6):937-44.

8. Albertini A, Djalle D, Faye B, Gamboa D, Luchavez J, Mationg ML, et al. Preliminary enquiry into the availability, price and quality of malaria rapid diagnostic tests in the private health sector of six malaria-endemic countries. Trop Med Int Health. 2012;17(2):147-52.

9. Uzochukwu BS, Chiegboka LO, Enwereuzo C, Nwosu U, Okorafor D, Onwujekwe OE, et al. Examining appropriate diagnosis and treatment of malaria: availability and use of rapid diagnostic tests and artemisinin-based combination therapy in public and private health facilities in south east Nigeria. BMC Public Health. 2010;10:486.

10. Kyabayinze D, Asiimwe C, Nakanjako D, Nabakooza J, Bajabaite M, Strachan C, et al. Programme level implementation of malaria rapid diagnostic tests (RDTs) use: outcomes and cost of training health workers at lower level health care facilities in Uganda. BMC Public Health. 2012;12(1):291.

11. Mbonye A, Magnussen P, Chandler C, Hansen K, Lal S, Cundill B, et al. Introducing rapid diagnostic tests for malaria into drug shops in Uganda: design and implementation of a cluster randomized trial. Trials. 2014;15(1):303.

12. Harvey $S$, Jennings $L$, Chinyama M, Masaninga $F$, Mulholland $K$, Bell D. Improving community health worker use of malaria rapid diagnostic tests in Zambia: package instructions, job aid and job aid-plus-training. Malar J. 2008;7(1):160.

13. Rennie W, Phetsouvanh R, Lupisan S, Vanisaveth V, Hongvanthong $B$ Phompida $\mathrm{S}$, et al. Minimising human error in malaria rapid diagnosis: clarity of written instructions and health worker performance. Trans R Soc Trop Med Hyg. 2007;101(1):9-18.

14. Mukanga D, Babirye R, Peterson S, Pariyo GW, Ojiambo G, Tibenderana JK, et al. Can lay community health workers be trained to use diagnostics to distinguish and treat malaria and pneumonia in children? Lessons from rural Uganda. Tropical Med Int Health. 2011;16(10):1234-42.

15. Counihan H, Harvey SA, Sekeseke-Chinyama M, Hamainza B, Banda R, Malambo T, et al. Community Health Workers use Malaria Rapid Diagnostic Tests (RDTs) safely and accurately: results of a longitudinal study in Zambia. AmJTrop Med Hyg. 2012;87(1):57-63.

16. Ndiaye Y, Ndiaye J, Cisse B, Blanas D, Bassene J, Manga I, et al. Community case management in malaria: review and perspectives after four years of operational experience in Saraya district, south-east Senegal. Malar J. 2013;12(1):240.

17. Okello G, Ndegwa S, Halliday K, Hanson K, Brooker S, Jones C. Local perceptions of intermittent screening and treatment for malaria in school children on the south coast of Kenya. Malar J. 2012;11(1):185. 
18. Nankabirwa J, Brooker SJ, Clarke SE, Fernando D, Gitonga CW, Schellenberg $D$, et al. Malaria in school-age children in Africa: an increasingly important challenge. Tropical Med Int Health. 2014;19(11):1294-309.

19. Mharakurwa S, Mutambu SL, Mberikunashe J, Thuma PE, Moss WJ, Mason PR. Changes in the burden of malaria following scale up of malaria control interventions in Mutasa District. Zimbabwe Malar J. 2013;12:223.

20. Pullan RL, Bukirwa H, Staedke SG, Snow RW, Brooker S. Plasmodium infection and its risk factors in eastern Uganda. Malar J. 2010;9:2.

21. Houngbedji C, N'Dri P, Hurlimann E, Yapi R, Silue K, Soro G, et al. Disparities of Plasmodium falciparum infection, malaria-related morbidity and access to malaria prevention and treatment among school-aged children: a national cross-sectional survey in Cote d'Ivoire. Malar J. 2015;14(1):7.

22. Feikin DR, Nguyen LM, Adazu K, Ombok M, Audi A, Slutsker L, et al. The impact of distance of residence from a peripheral health facility on pediatric health utilisation in rural western Kenya. Trop Med Int Health. 2009;14(1):54-61.

23. Raso G, Utzinger J, Silué KD, Ouattara M, Yapi A, Toty A, et al. Disparities in parasitic infections, perceived ill health and access to health care among poorer and less poor schoolchildren of rural Côte d'Ivoire. Tropical Med Int Health. 2005;10(1):42-57.

24. Abiiro GA, Mbera GB, De Allegri M. Gaps in universal health coverage in Malawi: a qualitative study in rural communities. BMC Health Serv Res. $2014 ; 14: 234$

25. Walldorf JA, Cohee LM, Coalson JE, Bauleni A, Nkanaunena K, Kapito-Tembo $A$, et al. School-age children are a reservoir of malaria infection in Malawi. PLoS One. 2015;10(7):e0134061.

26. Pasha O, Rosso JD, Mukaka M, Marsh D. The effect of providing fansidar (sulfadoxine-pyrimethamine) in schools on mortality in school-age children in Malawi. Lancet. 2003;361(9357):577-8.

27. Simwaka BN, Simwaka K, Bello G. Retrospective analysis of a school-based malaria treatment programme demonstrates a positive impact on health and education outcomes in Mangochi district, Malawi. J Dev Effectiveness. 2009;1(4):492-506.

28. Afenyadu GY, Agyepong IA, Barnish G, Adjei S. Improving access to early treatment of malaria: a trial with primary school teachers as care providers. Tropical Med Int Health. 2005;10(10):1065-72.

29. Magnussen P, Ndawi B, Sheshe AK, Byskov J, Mbwana K. Malaria diagnosis and treatment administered by teachers in primary schools in Tanzania. Tropical Med Int Health. 2001:6(4):273-9.

30. Bennett A, Kazembe L, Mathanga DP, Kinyoki D, Ali D, Snow RW, et al. Mapping malaria transmission intensity in Malawi, 2000-2010. Am J Trop Med Hyg. 2013;89(5):840-9.

31. SACMEQ. The Southern and Eastern Africa consortium for monitoring educational quality. Malawi: Education fact sheet; 2009.

32. The USAID Quality Assurance Project (QAP), University Research Co., LLC, and the World Health Organization (WHO). How to use a rapid diagnostic test (RDT): a guide for training at a village and clinic level (Modified for training in the use of the Generic Pf Test for falciparum malaria): How To Do the Rapid Test for Malaria. Bethesda, MD, and Geneva. 2009.

33. Rennie W, Phetsouvanh R, Lupisan S, Vanisaveth V, Hongvanthong B, Phompida $\mathrm{S}$, et al. Minimising human error in malaria rapid diagnosis: clarity of written instructions and health worker performance. Trans R Soc Trop Med Hyg. 2007;101(1):9-18.

34. Seidahmed OME, Mohamedein MMN, Elsir AA, Ali FT, Malik EFM, Ahmed ES. End-user errors in applying two malaria rapid diagnostic tests in a remote area of Sudan. Tropical Med Int Health. 2008;13(3):406-9.

35. Hopkins H, Oyibo W, Luchavez J, Mationg M, Asiimwe C, Albertini A, et al. Blood transfer devices for malaria rapid diagnostic tests: evaluation of accuracy, safety and ease of use. Malar J. 2011;10(1):30.

36. Luchavez J, Lintag ME, Coll-Black M, Baik F, Bell D. An assessment of various blood collection and transfer methods used for malaria rapid diagnostic tests. Malar J. 2007:6(1):149.

37. The USAID Quality Assurance Project (QAP), University Research Co., LLC, and the World Health Organization (WHO). How to use a rapid diagnostic test (RDT): A guide for training at a village and clinic level (Modified for training in the use of the Generic Pf Test for falciparum malaria): Sample test \#1: Generic Pf RDT Quiz ver.1. Bethesda, MD, and Geneva. 2009.

38. Charlin B, Roy L, Brailovsky C, Goulet F, van der Vleuten C. The script concordance test: a tool to assess the reflective Clinician. Teach Learn Med. 2000;12(4):189-95.
39. Dory V, Gagnon R, Vanpee D, Charlin B. How to construct and implement script concordance tests: insights from a systematic review. Med Educ. 2012;46(6):552-63.

40. Charlin B, Gagnon R, Lubarsky S, Lambert C, Meterissian S, Chalk C, et al. Assessment in the context of uncertainty using the script concordance test: more meaning for scores. Teach Learn Med. 2010;22(3):180-6.

41. Duggan P, Charlin B. Summative assessment of 5 th year medical students clinical reasoning by script concordance test: requirements and challenges. BMC Med Educ. 2012;12(1):29.

42. Asiimwe C, Kyabayinze D, Kyalisiima Z, Nabakooza J, Bajabaite M, Counihan $\mathrm{H}$, et al. Early experiences on the feasibility, acceptability, and use of malaria rapid diagnostic tests at peripheral health centres in Uganda-insights into some barriers and facilitators. Implement Sci. 2012;7(1):5.

43. Hawkes M, Katsuva J, Masumbuko C. Use and limitations of malaria rapid diagnostic testing by community health workers in war-torn Democratic Republic of Congo. Malar J. 2009;8(1):308.

44. Moonasar D, Goga AE, Frean J, Kruger P, Maharaj R, Chandramohan D. Primary health workers' proficiency in using malaria rapid diagnostic tests in Limpopo Province. S Afr Med J. 2009;99(11):798-9.

45. Gagnon R, Charlin B, Lambert C, Carrière B, Vleuten C. Script concordance testing: more cases or more questions? Adv Health Sci Educ. 2009;14(3):367-75

46. Lubarsky S, Charlin B, Cook DA, Chalk C, van der Vleuten CPM. Script concordance testing: a review of published validity evidence. Med Educ. 2011:45(4):329-38

47. Gagnon R, Charlin B, Coletti M, Sauvé E, Van Der Vleuten C. Assessment in the context of uncertainty: how many members are needed on the panel of reference of a script concordance test? Med Educ. 2005;39(3):284-91.

48. Ndyomugenyi R, Clarke S, Magnussen P, Hansen K, Lynch C. Uganda National Malaria Control Programe \& ACT Consortium. Use of artemisinin based combination therapies and rapid diagnostic tests for home-based management of fever in Uganda, rapid diagnostic test (RDT) arm, reference manual for community medicine distributors. 2010. Available at www.actconsortium.org/RDThomemanagement.

\section{Submit your next manuscript to BioMed Central and take full advantage of:}

- Convenient online submission

- Thorough peer review

- No space constraints or color figure charges

- Immediate publication on acceptance

- Inclusion in PubMed, CAS, Scopus and Google Scholar

- Research which is freely available for redistribution 